\title{
Çocukların Sosyobilimsel Konulara Yönelik Tutumları Ölçeğinin Geçerlik ve Güvenirlik Çalışması
}

DOI: $10.26466 /$ opus.932976

\author{
Menșure Alkıș Küçükaydın * - Yasin Gökbulut ** - Dilek Şahinpınar *** \\ ${ }^{*}$ Doç. Dr., Necmettin Erbakan Üniversitesi, Konya/Türkiye \\ E-Posta: mensurealkis@hotmail.com \\ ORCID: $0000-0003-4410-1279$ \\ ** Doç Dr., Gaziosmanpaşa Üniversitesi, Tokat/Türkiye \\ E-Posta: yasin.gokbulut@gop.edu.tr \\ ORCID: $\underline{0000-0001-8554-1102}$ \\ *** Öğr. Gör., Ağrr İbrahim Çeçen Üniversitesi, Ağrr/Türkiye \\ E-Posta: dsahinpinar@agri.edu.tr \\ ORCID: 0000-0001-9454-5808
}

Öz

Bu çalışmanın amacl, Klaver ve van der Molen (2020) tarafindan geliştirilen Çocuklarm Sosyobilimsel Konulara Yönelik Tutumları Ölçeğinin Türkçeye uyarlanarak ölçeğe ilişskin geçerlik ve güvenirlik analizlerini yapmaktır. Ölçek uyarlamasinda veriler Konya ve Tokat illerinde 4.,5.,6., 7. ve 8.simflarda öğrenim gören öğrencilerden toplanmıştır. Bu kapsamda ilkokul kademesinden 216, ortaokul kademesinden 284 öğrenciden veri toplanmıştır. İlgili veriler açımlayıcı ve doğrulayıcı faktör analizlerine tabii tutulmuştur. Açımlayıcı faktör analizi sonucunda ölçeğin "kişisel ilgi", "okul ilgi düzeyi", "olumlu duygular", "endişe", "ortak yeterlik" ve "başkalarına bağımllık" olmak üzere 6 faktörlü bir yapıya sahip olduğu görülmüsşür. Ortaya çıkan faktör yapısı birinci ve ikinci düzey doğrulayıcı faktör analizleri ile test edilmiştir. İlgili analizler doğrultusunda ölçeğe ilişskin iç güvenirlik katsayıları hesaplanmıştır. Buna göre Cronbach Alpha güvenilirlik katsayısı ölçeğin tamamı için 941 bulunmuştur. Ayrıca güvenirlik katsayıları "kişisel ilgi" için .787, "okul ilgi düzeyi" için .886, "olumlu duygular" için .859, "endişe" için .907, "ortak yeterlik" için .944 ve "başkalarına bağımlllı" için .881 olarak hesaplanmıştır. Ayrıca ölçeğe ilişkin madde toplam korelasyon değerleri ile faktörler arası korelasyon değerleri ele alınmıştır. Doğrulayıcı faktör analizi ölçeğe ilişkin model uyum değerlerinin iyi uyumda olduğunu göstermiştir. İlgili sonuçlar ölçeğin geçerli ve güvenilir bir ölçme aracı olarak kullanılabileceğini işaret etmektedir.

Anahtar Kelimeler: öğrenci, ölçek uyarlama, sosyobilimsel konular. 


\title{
The Study of Validity and Reliability of Pupils' Attitudes towards Socioscientific Issues Scale
}

\begin{abstract}
The aim of this research is to adapt the Pupils' Attitudes towards Socioscientific Issues Scale (Klaver $\mathcal{E}$ van der Molen, 2020) to Turkish and to examine its psychometric properties. The study group consists of the students studying in the 4 th 5 th, 6 th, 7 th and 8 th grade classes of basic education schools in Konya and Tokat city center. In this context, data were collected from 216 students from the primary school level and 284 students from the secondary school level. The relevant data was subjected to exploratory and confirmatory factor analyzes. As a result of the exploratory factor analysis, it was seen that the scale has a 6-factor structure: "personal relevance", "relevance school", "positive feelings", "concern", "collective efficacy" and "dependency on others". The resulting factor structure was tested with first and second level confirmatory factor analyzes. Internal reliability coefficients for the scale were calculated in line with the relevant analyzes. Accordingly, the Cronbach Alpha reliability coefficient was calculated as .941 for the whole scale. In addition, the reliability coefficients were .787 for "personal relevance, .886 for "relevance school", .859 for "positive feelings", .907 for "concern", .944 for "collective efficacy" and .881 for "dependency on others" as calculated. The item-total correlation values for the scale and the correlation values between the factors were also calculated. Confirmatory factor analysis showed that the model fit values for the scale were in good fit. The scale can be used as a valid and reliable measurement tool used to collect data.
\end{abstract}

Keywords: primary school students, scale adaptation, socioscientific issues. 


\section{Giriş}

Fen eğitiminin temel hedeflerinden biri öğrencilerin okulda öğrendikleri bilgiyi günlük yaşamlarına transfer etmelerini sağlamaktır (Alkış Küçükaydın, 2019a). Bu beklenti dünya genelindeki pek çok fen eğitimi programında kendine yer bulmuştur (National Research Council, 2011; OECD, 2014). Ülkemizde de Milli Eğitim Bakanlığı (2018) fen bilimleri dersi öğretim programı özel amaçlarında; "Günlük yaşam sorunlarnna ilişkin sorumluluk alınmastnu ve bu sorunlar çözmede fen bilimlerine ilişkin bilgi, bilimsel süreç becerileri ve diğer yaşam becerilerinin kullamılmasın sağlamak" (s.9) ifadesine yer vermiştir. Öğrencilerin hem bilimin içinde yer alması hem de günlük yaşamın içinde bilim öğrenmeleri ilgili literatürde sosyobilimsel konular (SBK) ile ilişkilendirilmiştir (Zeidler, 2014). SBK; fen eğitiminde tartışmalı konuların genel karakterini yansıtmakta olup bilimsel okuryazarlığın işlevselliğini ön plana çıarmaktadır (Elam, Solli ve Mäkitalo, 2019). SBK bağlamında sunulan bir problem üzerinde öğrencilerin sorumlu karar almaları beklenmekte, zihinsel bir çatışmaya girerek bilimsel bilginin sosyal yapısı da açığa çıkarılmaktadır (Rubini, Ardianto, Setyaningsih ve Sariningrum, 2019).

SBK; bilimsel konuların kasıtlı bir şekilde farklı bağlamlardan tartışılmasını içermektedir. Ancak bu tartışmalarda varılacak nihai kararlar üzerinde öğrencilerin sahip olduğu tutum, etik ve ahlaki yargılar oldukça yönlendirici olmaktadır (Zeidler ve Nichols, 2009). Öğrencilerin sahip olduğu bu farklı bakış açları sınıf ortamında oldukça değerlidir. Çünkü SBK'ların fen öğretimine dâhil edilmesi esnasında sınıfta yürütülecek tartışmalar, öğrencilerin başkalarının bakış açıların görmelerini, farklı fikirlere saygı duymayı öğrenmelerini ve bilimsel anlamda rakip iddiaları sentezlemelerini sağlamakta ayrıca etik konulardaki duyarlılığın artmasına hizmet etmektedir (Zeidler, 2014). Böylece SBK ile bilim ve toplum arasında köprü kurulmuş olmaktadır (Sadler, 2004). Chowdhury, Holbrook ve Rannikmäe (2020) SBK literatürünü dolayısıyla SBK tanımlarını 10 boyut altında toplamışlardır. Bunlar; SBK'nın tartışmalı doğası, SBK bağlamının yapılandırılmış olması, gerçek yaşamla bağlantılı olması, ahlaki, etik ve değer açıklamalarını kapsaması, bilimsel ve kavramsal bir bağlamının olması, öğretim programıyla ilişkilendirilmesi ve argümantasyonla uyumlu bir yapısının olması şeklindedir. Bununla beraber SBK bağlamında seçilen konuların net bir çözümü yoktur dolayısıyla bu durum öğrencilerin SBK tartışmalarına aktif bir şekilde ka- 
tılmalarını gerekli kılar (Zeidler ve Kahn, 2014). Bu tartışmalarda öğrenciler, demokratik kararlar almayı da öğrenirler. Çünkü alacakları kararın toplumun her kesimi üzerindeki etkisini öngörmeleri gerekmektedir. Bu öngörüş öğrencilerin işlevsel bilim okuryazarlıklarının gelişimini destekleyerek vatandaşlık bilincinin kazandırılmasına da hizmet etmektedir (Sadler, 2011). Lee ve arkadaşları (2013) fen eğitiminde karakter ve değer gelişimini bu açıdan önemli görmüşler ve SBK temeli öğretimi önermişlerdir.

SBK tartışmalarında öğrenciler kendi değer yargilarını geliştirmekte dolayısıyla sürece duygularını da katmaktadırlar. Çünkü tartışmalara farklı değer yargıları karışmakta, nihai karara ulaşıncaya kadar öğrencilerin kafaları karışmakta ve duygusal anlamda çatışma yaşamaktadırlar (Gao, Mun ve Kim, 2019). Dolayısıyla SBK tartışmaları öğrencileri hem bilişsel ve duyuşsal anlamda etkilemekte hem de küresel vatandaşlık olgusunun oluşmasında etkili olmaktadır. SBK'nın bilişsel boyutuna değinen çalışmalar; SBK'nın argümantasyonla ilişkisi (Alkış Küçükaydın, 2019b; Atabey ve Topcu, 2017), SBK'nın informal muhakeme becerileri üzerindeki etkisi (Akbaş ve Çetin, 2018; Atasoy, 2018) ve SBK ile sorgulama becerileri arasındaki ilişki (Alkış Küçükaydın, 2019c) bağlamında ele alınmıştır. Duyuşsal boyutta ise değer yargılarının oluşumu (Türksever, Karışan ve Türkoğlu, 2020), tutum (Ayvacı, Bülbül ve Türker, 2019; Erkol ve Gül, 2020) ve inanç çalışmalarının (Sevim ve Ayvacı, 2020) yürütüldüğü görülmektedir. Ancak ilgili çalışmaların büyük çoğunluğunun öğretmen adaylarıyla yürütüldüğü görülmekte özellikle öğretmen adaylarına yönelik olarak tutum çalışmalarında geçerli ve güvenilir ölçme araçlarının varlığı işaret edilmektedir (Topçu, 2010).

Fen eğitimi araştırmaları, öğrencilerin SBK hakkında akıl yürütmeleri üzerine bilimsel bilginin önemli olduğunu işaret etmektedir (Xiao ve Sandoval, 2017). Ancak bilimsel bilgiye sahip olmak tek başına akıl yürütme becerisi için yeterli görünmemektedir. Sahip olunan etik ve ahlaki değerler, ekonomik kaygılar ya da toplumsal anlayış, bireyin SBK hakkındaki akıl yürütmeleri üzerinde etkili olmaktadır (Özden, 2020). Örneğin Raveendran'ın (2021) bir grup Hintli öğrenciyle ticari amaçlı taşıyıcı annelik konusunu ele aldıkları SBK tartışmalarında, öğrencilerin farklı görüşlerinin olduğu ve bu görüşler altında yatan politik-etik değer yapılarının olduğu görülmüştür. Hintli öğrenciler ticari amaçlı taşıyıcı anneliği kast, cinsiyet ve sınıfsal farkındalık açısından ele almış ve SBK bağlamına farklı açılardan yaklaşmı̧̧- 
lardır. Yetişkinlerle yürütülen diğer pek çok çalışma (Chowdhury vd., 2020; Ladachart ve Ladachart, 2021; Yerdelen, Cansiz, Cansiz ve Akcay, 2018) ile elde edilen bu sonuçlar, çocukların SBK bağlamında nasıl bir tutuma sahip oldukları sorusunu akla getirmektedir. Kimi çalışmalarda fene yönelik tutum konusu ele alınmış olmakla birlikte (Bozdağ, 2019; Ocak ve Erbasan, 2017; Uyanık, 2017) tartışmalı ve sosyal yaşamla ilişkilendirilmiş SBK'ya yönelik olarak çocukların tutumlarının ne olduğu henüz araştırılmamıştır. Böylesi bir araştırma çocukların SBK konusunda ne türde bir yargıya sahip olduklarının açı̆̆a çıkarılması bakımından değerli görülmektedir. Dolayısıyla çocukların bu yöndeki tutumlarını açığa çıkarmak için geçerli ve güvenilir araçların kullanılması gereklidir. Bu çalışmada da ilgili literatürde yer alan ve çocukların SBK'ya yönelik tutumlarını açı̆̆a çıkarmak amaciyla geliştirilmiş bir ölçme aracının Türk diline ve kültürüne uyarlanması hedeflenmiştir.

\section{Çocukların Sosyobilimsel Konulara Yönelik Tutumları Ölçeğinin Tanı- tılmasi}

Çocukların Sosyobilimsel Konulara Yönelik Tutumları Ölçeği, Klaver ve van der Molen (2020) tarafından 8-15 yaş grubundaki çocuklarla yürütülecek çalışmalarda kullanılmak üzere geliştirilmiştir. İlgili ölçek Hollanda'da 382 ilkokul, 988 ortaokul kademesinde olmak üzere toplam 1370 çocuğa uygulanmış ve ölçeğin yazım aşamasında İngilizceye çevrilmiştir. Ölçek; kurumsal ilgi (relevance institutions), kişisel ilgi (personal relevance), okul ilgisi düzeyi (relevance school), olumlu duygular (positive feelings), endişe (concern), öz-yeterlik (self-efficacy), ortak yeterlik (collective efficacy) ve başkalarına bağımlılık (dependency on others) olmak üzere 8 faktörlü bir yapıdan oluşmaktadır. Ölçeğin birinci faktöründe 3, ikinci faktöründe 4, üçüncü faktöründe 4 , dördüncü faktöründe 4 , beşinci faktöründe 3 , altıncı faktöründe 3 , yedinci faktöründe 4 ve sekizinci faktöründe 2 olmak üzere toplam 27 madde yer almıştır. Ölçek; "Kesinlikle Katılıyorum", "Katılıyorum", "Katılmıyorum" ve "Kesinlikle Katılmıyorum" ifadelerinden oluşan 4'lü Likert tipindedir. Ölçekte ters kodlanacak madde bulunmamaktadır.

Çocukların Sosyobilimsel Konulara Yönelik Tutumları Ölçeği için Spearman-Brown analizi yapılmış ve ölçeğin tamamı için .54 değerine ulaşılmıştır. Klaver ve van der Molen (2020) geliştirdikleri ölçek ile ilkokul ve 
ortaokul öğrencilerinin SBK'ya yönelik tutumlarını ölçmüş ve farklı yaş gruplarındaki öğrencilerin tutumları arasında bir farklılığın olmadığını belirtmiştir. Dolayısıyla ilgili ölçeğin ilk ve ortaokul kademesinde kullanılabilir geçerli ve güvenilir bir ölçme aracı olduğu belirtilmiştir.

\section{Çalışmanın Amacı}

Bu çalışmanın amacı Klaver ve van der Molen (2020) tarafından Hollandalı ögrencilerle yürütülen ve sonrasında İngilizceye çevrilen bir ölçeğin Türkçeye uyarlamasının yapılmasıdır. Böylece ilgili ölçeğin geçerlik ve güvenirlik çalışmalarının yapılarak uyarlama sonrası gerçek faktör yapısı belirlenerek Türk çocuklarının SBK'ya yönelik tutumlarının belirlenmesine hizmet edilmiş olacaktır.

\section{Yöntem}

Bu çalışmada nicel araştırma yöntemlerinden tarama deseni benimsenmiştir. Tarama çalışmaları; evreni ya da evreni temsil eden örneklemin yetenek, tutum, inanç gibi özelliklerini belirlemek amacıyla uygun araçlar kullanılarak verilerin toplanması esasına dayanır (Sezgin Selçuk, 2019). Bu çalışmada da ölçek uyarlaması amacıyla evreni temsil eden bir örneklem üzerinden veriler tarama yöntemiyle toplanmıştır.

\section{Örneklem}

Çalışmanın evrenini 2020-2021 akademik yılında Konya ve Tokat illerinde öğrenim görmekte olan 4.,5.,6.,7 ve 8.sınıf öğrencileri oluşturmuştur. Çalışmanın örneklem seçiminde ise evrende bulunan her bireye çalışmaya dâhil olma açısından eşit şans sunan basit seçkisiz örneklem tekniği (Büyüköztürk, Kılıç Çakmak, Akgün, Karadeniz ve Demirel, 2011) kullanılmıştır. İlgili ölçeğin orijinalinde araştırmacilar 8-15 yaş grubunu çalışmaya dâhil etmişlerdir (Klaver ve van der Molen, 2020). Ancak gerek kültür yapısı gerekse ilkokul fen bilimleri ders programında yer alan SBK kazanımlarının varlığı gözetilerek bu uyarlama çalışmasına ilkokul düzeyinden sadece 4 .sınıf öğrencileri dâhil edilmiştir. Böylece ilgili ölçeğin daha anlaşılır ve anlamlı ola- 
cağı düşünülmüştür. Bu hedefle oluşturulan örnekleme ait demografik bilgiler Tablo 1'de sunulmuştur.

Tablo 1. Örneklemin demografik özellikleri

\begin{tabular}{|c|c|c|c|c|c|c|c|}
\hline & & \multicolumn{5}{|c|}{ Öğrenim Görülen Sınıf } & \multirow[b]{2}{*}{ Toplam } \\
\hline & & $4 . \operatorname{sinif}$ & 5.sinif & $6 . \operatorname{sinf}$ & 7.sinif & 8.sinif & \\
\hline \multirow[t]{2}{*}{ Cinsiyet } & $\mathrm{K} 1 \mathrm{z}$ & 115 & 30 & 40 & 58 & 64 & 307 \\
\hline & Erkek & 101 & 18 & 19 & 35 & 20 & 193 \\
\hline Toplam & & 216 & 48 & 59 & 93 & 84 & 500 \\
\hline
\end{tabular}

Tablo 1'e göre ilgili çalışmaya toplam 307 kız ve 193 erkek öğrenci katılmıştır. Öğrencilerin 216'sı ilkokul kademesinde 284'ü ise ortaokul kademesinde öğrenim görmektedir. Dolayısıyla ilk ve ortaokul kademesinden çalı̧̧maya katılan öğrenci sayılarının birbirine yakın olduğu görülmektedir.

\section{Veri Toplama Araçları}

Çalışmada Klaver ve van der Molen (2020) tarafından geliştirilen ölçek yardımıyla veriler toplanmıştır. Veriler 2 bölümden oluşan bir form yardımıyla toplanmıştır. Formun ilk bölümünde öğrencilerin cinsiyetleri ve sınıf düzeyleri bilgisi sorulmuştur. Formun ikinci bölümünde ise ilgili ölçek maddelerine yer verilmiştir. Uyarlaması yapılacak ölçek 4'lü Likert tipinde olup toplam 27 maddeden oluşmaktadır.

İki bölümden oluşan uygulama formu, öğrencilere yüz yüze ve çevrim içi platformlar aracilığıyla uygulanmıştır. Küresel salgın sebebiyle okulların kapanması ve 8 .sınıflar dışında öğrencilerin okula gelmemesi durumuna bağlı olarak ilgili form, her iki şekilde de öğrencilere ulaştırılmıştır. Okullarına devam eden öğrenciler için formlar okullarına bırakılmış ve doldurulduktan sonra geri toplanmıştır. Okullarına devam edemeyen öğrenciler için ise ilgili form Google Forms yardımıyla öğretmenlerine ulaştırılmış ve bu şekilde dönüş elde edilmiştir.

\section{Ölçeğin Türkçeye Uyarlanması}

İlgili ölçek için yazarlardan izin alındıktan sonra bu çalışmanın araştırmacıları ölçek maddelerini Türkçeye çevirmişlerdir. İlgili ölçek aynı zamanda birbirinden bağımsız 2 dil uzmanına gönderilmiş ve Türkçeye çevirmeleri 
istenmiştir. Araştırmacıların ve dil uzmanlarının yaptığı çeviriler bir araya getirilerek ayrı bir dil uzmanı ile alan uzmanının görüşüne sunulmuştur. Uzmanlardan gelen görüşler çevirilerin birbiriyle uyumlu olduğunu göstermiştir. Bunun üzerine Türkçeye çevrilmiş ölçek yeniden orijinal diline çevrilmek üzere ilk aşamada yer alan dil uzmanlarından farklı 2 kişiye ve bu alanda doktorasını tamamlamış bir alan uzmanına gönderilmiştir. Dil uzmanlarından gelen çeviriler arasında kimi kavramlar arasında farklılıklar olduğu görülmüş (örneğin should, must kalıpları) bunun üzerine görüş almak üzere üçüncü bir dil uzmanından görüş istenmiştir. Alınan görüşler doğrultusunda gerek yapısal gerek anlamsal açıdan çeviride bir sorun olmadığı belirtilmiştir. Alan uzmanının görüşleri doğrultusunda ölçeğin Türkçe formu oluşturulmuştur. Sonraki aşamada Türkçe formun Türk dil yapısı, anlam ve gramer açısından uygunluğunu kontrol etmesi için biri Türkçe eğitimi alanında doktoralı uzman diğer ise 12 yıllık deneyimi olan bir Türkçe öğretmeninden görüş alınmıştır. Alınan görüşlere göre ilgili forma son hali verilmiştir. Son olarak uygulamaya geçilmeden önce ölçeğin anlaşılırlığını test etmek için örneklem dışından seçilen ve dördüncü sınıfta öğrenim gören 4 öğrenci ile ölçeğin pilot uygulaması yapılmıştır. Öğrencilerin dönütleri de alındıktan sonra gerçek uygulamaya geçilmiştir.

\section{Verilerin Analizi}

Ölçme araçlarının uyarlama sürecinde açımlayıc faktör analizi (AFA) ile doğrulayıc faktör analizi (DFA) olmak üzere iki tipte faktör analizi yaklaşımı benimsenmektedir. AFA'da ölçeğin örtük yapısı ortaya çıkarılmaya çalışılırken DFA'da AFA ile belirlenen örtük yapının doğrulanması söz konusudur (Seçer, 2015). Ancak ilgili ölçek uyarlamasında örtük yapının belirlenmesi için yeterli örneklem büyüklügüne ulaşılması gereklidir. İlgili literatürde bu konuda farklı görüşler yer almaktadır. Kimi kaynaklar yeterli örneklem sayısınin en az 300 (Field, 2005) kimi kaynaklar ise 250 olması gerektiğini (Hoyle, 1995) belirtmiştir. Bunun yanı sıra Gorsuch (1983) ölçekte yer alan her madde için en az 5 kişi, Everitt (1975) her madde için en az 10 kişi, Tinsley ve Kass (1979) ise madde sayısının en az 5 katı büyüklükte bir örnekleme ihtiyacı olduğunu belirtmiştir. Tüm literatür birlikte değerlendirildiğinde 27 maddelik ölçek için ortalama 300 kişilik bir örnekleme ihtiyaç duyulduğu görülmektedir. Bu çalı̧̧mada da toplam 500 kişiye ulaşılmıştır. 
Dolayısıyla örneklem büyüklüğünün faktör analizleri için yeterli olduğu söylenebilir.

\section{Bulgular}

\section{Açımlayıcı Faktör Analizi}

Uyarlaması yapılacak ölçeğin ilk olarak AFA'ya uygunluğunu test etmek amacıyla Kaiser-Meyer- Olkin (KMO) ve Bartlett testleri yapılmışır (Tablo 2). İlgili test sonuçları KMO değerinin .894 ve Barlett testinin $p<.01$ düzeyinde anlamlı olduğunu dolayısıyla ölçek verileri için AFA'nın yapılabileceğini göstermiştir (Field, 2005). AFA'da ilgili maddelerin öz değerlerinin en az 1, madde faktör yüklerinin ise en az .30 seviyesinde olmasına dikkat edilmiştir. Maddelerin tek bir faktöre ait olması, iki faktörde yer alan madde var ise faktör yükleri arasında en az .10 fark olmasına dikkat edilmiştir (Seçer, 2013).

Tablo 2. KMO ve Barlett test sonuçlan

\begin{tabular}{lll}
\hline KMO & & .894 \\
\hline \multirow{3}{*}{ Barlett Testi } & $\chi^{2}$ & 4764.900 \\
& sd & 120 \\
& $p$ & .000 \\
\hline
\end{tabular}

$\mathrm{Bu}$ aşamadan sonra ilgili veri seti üzerinden ölçeğin örtük yapısının ortaya çıarılması amacıyla faktör analizine geçilmiştir. İlgili ölçeğin faktör yapısını ortaya koymak için temel bileşenler analiz yöntemi kullanılmıştır (Seçer, 2015). Uç değerler, normallik ve çoklu doğrusallık analizleri yapılmıştır. Normallik varsayımlarını karşılamayan 2 madde (1 ve 8.maddeler) analizden çıkarılmıştır. Faktör analizinde Kaiser-Guttman ilkesine göre özdeğerleri 1'den büyük ve açıklanan toplam varyansa katkısı en az \%5 olan faktör yapısının olmasına dikkat edilmiştir (Büyüköztürk, 2011). Ölçekteki faktörlerin birbirleriyle ilişkili olduğu varsayılarak ortogonal döndürme tekniklerinden varimax kullanılmıştır. Bu döndürme tekniğinde, faktör eksenlerinin konumları değiştirilmeksizin 90 derecelik açıyla döndürülmesi söz konusudur (Seçer, 2013). Bu hususlar dikkate alınarak gerçekleştirilen AFA sonucunda öz değeri 1'den yüksek 6 faktör elde edilmiştir. 6 faktörlü bu yapıya ilişkin faktör yük değerleri Tablo 3 'de özetlenmiştir. 
Tablo 3. Faktör yük değerleri

\begin{tabular}{|c|c|c|c|c|c|c|c|c|}
\hline & \multicolumn{6}{|c|}{ Faktörler } & \multicolumn{2}{|c|}{ Ortak Faktör Madde Toplam } \\
\hline & 1 & 2 & 3 & 4 & 5 & 6 & Varyansı & Korelasyonu \\
\hline $\mathrm{M} 4$ & 658 & & & & & & 619 & .606 \\
\hline M5 & .664 & .328 & & & & & .641 & .647 \\
\hline M6 & .760 & & & & & & .672 & .612 \\
\hline M7 & .843 & & & & & & .834 & .856 \\
\hline M9 & & .784 & & & & & .800 & .770 \\
\hline M10 & & .801 & & & & & .825 & .797 \\
\hline M11 & & .772 & & & & & .801 & .773 \\
\hline M13 & & & .842 & & & & .838 & .776 \\
\hline M14 & & & .782 & & & & .813 & .757 \\
\hline M15 & & & .670 & & & & .686 & 679 \\
\hline M16 & & & & .782 & & & .791 & .813 \\
\hline M17 & & & & .874 & & & .881 & .785 \\
\hline M18 & & & & .842 & & & .840 & .850 \\
\hline M22 & & & & & .870 & & .847 & .867 \\
\hline M23 & & & & & .843 & & .834 & .856 \\
\hline M24 & & & & & .883 & & .857 & .878 \\
\hline M25 & & & & & .873 & & .843 & .866 \\
\hline M26 & & & & & & .873 & .879 & .787 \\
\hline M27 & & & & & & .863 & .879 & .787 \\
\hline Öz Değer & 2.469 & 2.427 & 2.217 & 2.559 & 3.481 & 1.796 & & \\
\hline $\begin{array}{l}\text { Açılanan Varyans Oranı } \\
(\%)=78.677\end{array}$ & 12.993 & 12.775 & 11.667 & 13.470 & 18.322 & 9.450 & & \\
\hline $\begin{array}{l}\text { Cronbah Alpha (Ölçĕgin } \\
\text { Geneli)=.941 }\end{array}$ & .787 & .886 & .859 & .907 & .944 & .881 & & \\
\hline
\end{tabular}

.30'un altındaki faktör yükleri tabloda gösterilmemiştir.

Tablo 3'e göre ölçekte yer alan maddeler 6 faktör altında toplanmıştır. Birinci faktör 4 maddeden oluşmakta ve bu maddelerin faktör yük değerleri .664 ile .843 arasında değişmektedir. İkinci faktörde 3 madde yer almakta olup maddelerin faktör yük değerleri .772 ile .801 arasında değişmiştir. Üçüncü faktörde 3 madde yer almakta ve maddelere ait faktör yükleri .670 ile .842 arasında değişmektedir. Dördüncü faktörde 3 madde yer almakta olup maddelere ait faktör yük değerleri .782 ile .874 arasında değişmektedir. Beşinci faktörde 4 madde yer almakta ve faktör yükleri .843 ile .883 arasında değişmektedir. Altıncı faktörde ise 2 madde yer almakta olup madde faktör yükleri .873 ve .863 'tür. Ölçeğe ait faktörlerin açkladığı toplam varyans \%78.677'dir. Elde edilen bu değer madde toplam varyansının ölçeğe ilişkin varyansın önemli bir bölümünü açıkladığını göstermektedir. Birinci faktör toplam varyansın \% 12.993'ünü, ikinci faktör toplam varyansın \%12.775'ini, üçüncü faktör toplam varyansın \%11.667'sini, dördüncü faktör toplam varyansın \%13.470'ini, beşinci faktör toplam varyansın \%18.322'sini ve altınc faktör toplam varyansın \% 9.450'sini açıklamaktadır. Ölçeğe ilişkin olarak 
madde toplam korelasyon değerleri de incelenmiştir. Bu kapsamda madde toplam korelasyon değerlerinin .878 ile .545 arasında sıralandığı görülmüştür. Bu değerlerin yorumlanmasinda madde toplam korelasyonu .30 ve üzerinde olan maddelerin ölçülecek özelliği ayırt etme açısından yeterli olduğu kabul edilmiştir (Büyüköztürk, 2011). Ölçeğe ilişkin iç tutarlılık analizleri sonucunda ise ölçeğin tamamına ilişkin Cronbach Alpa değerinin .941 olduğu görülmüştür. Ölçeği oluşturan faktörlere ilişkin Cronbach Alpha değerleri sırasıyla $.787, .886, .859, .907, .944$ ve .881 olarak tespit edilmiştir.

İlgili ölçeğin faktörleri arasındaki ilişkiyi belirlemek amacıyla faktörler arası korelasyon da incelenmiştir. İlgili değerlerin .90 üzerinde olmadığ (Tablo 4) bu nedenle çoklu bağlantı probleminin yaşanmadığı gözlemlenmiştir (Field, 2005). Ölçeğe ilişkin AFA yapıldıktan sonra DFA'ya geçilmiştir.

Tablo 4. Ölçeğe ilişkin faktörler arası korelasyonlar

\begin{tabular}{lllllll}
\hline & $\mathbf{1}$ & $\mathbf{2}$ & $\mathbf{3}$ & $\mathbf{4}$ & $\mathbf{5}$ & $\mathbf{6}$ \\
\hline 1 & 1 & & & & & \\
2 & $.591^{*}$ & 1 & & & & \\
3 & $.537^{*}$ & $.540^{*}$ & 1 & & & \\
4 & $.488^{*}$ & $.574^{*}$ & $.481^{*}$ & 1 & & \\
5 & $.391^{*}$ & $.423^{*}$ & $.537^{*}$ & $.352^{*}$ & 1 & \\
6 & $.421^{*}$ & $.394^{*}$ & $.404^{*}$ & $.419^{*}$ & $.399^{*}$ & 1 \\
\hline${ }^{*} p<.01(2$-tailed). & & & & &
\end{tabular}

\section{Doğrulayıcı Faktör Analizi}

Çalışmada yapılan AFA'ya göre ilgili ölçeğin 6 faktörlü ve toplamda 19 maddeli bir yapıya sahip olduğu görülmüştür. Ortaya çıkan bu yapı DFA ile test edilmiştir. 6 faktör ve 19 maddelik ölçeğin birinci düzey faktöriyel yapıs1, AMOS 26.0 programı kullanılarak test edilmiştir. Verilerin normal dağılım göstermesi nedeniyle maximum likelihood hesaplama yöntemi (Gürbüz ve Şahin, 2018) kullanılmıştır. Ölçeğin birinci düzey çok faktörlü DFA sonuçlarına ilişkin diyagram Şekil 1'de sunulmuştur. Birinci düzey DFA neticesinde elde edilen uyum iyiliği değerlerinin $\left(\chi^{2}[137, N=500]=\right.$ 346.891; $\left.p<.01 ; \chi^{2} / \mathrm{sd}=2.532 ; \mathrm{RMSEA}=.055 ; \mathrm{CFI}=.967 ; \mathrm{GFI}=.931\right)$ önerilen 6 faktörlü modelin verileri ile uyumlu ve kabul edilebilir olduğu görülmektedir. Bu sonuçlar, çalışmadan elde edilen verilerin çocukların sosyobilimsel 
konulara yönelik tutumları ölçeğinin öngörülen kuramsal yapısı ile uyuştuğunu göstermektedir.

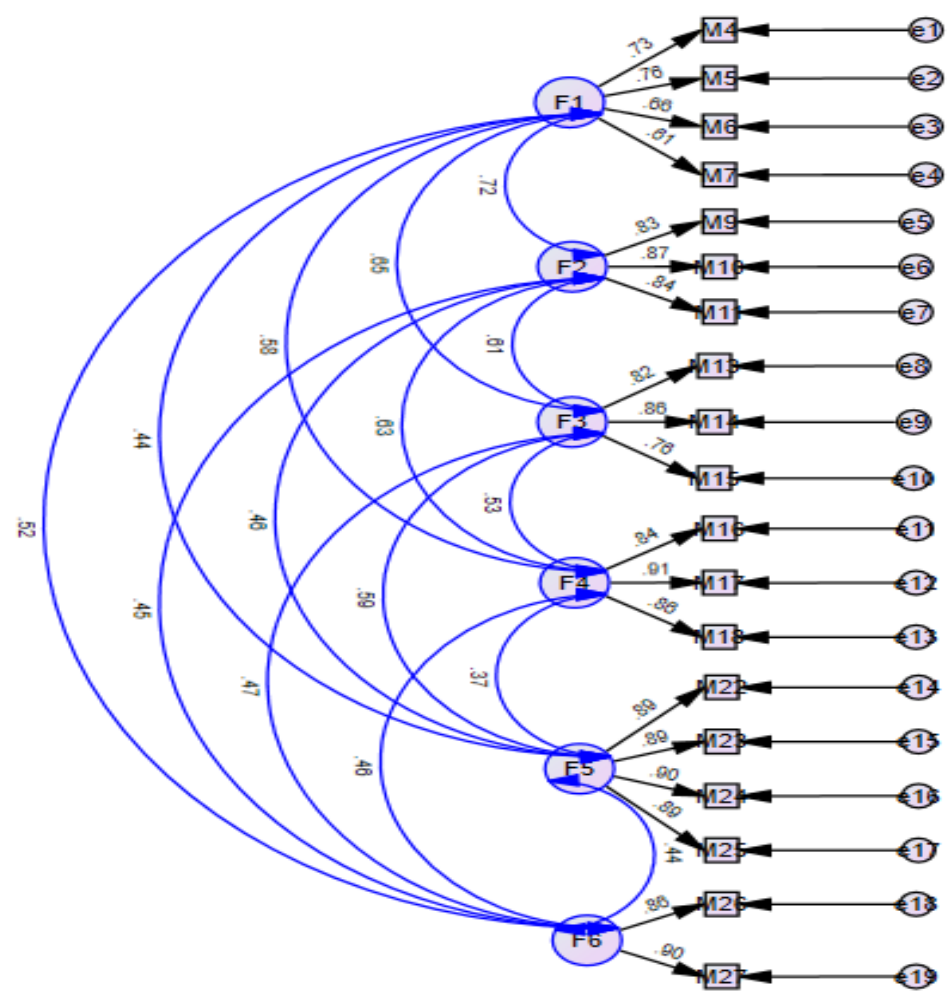

Şekil 1. Ölçeğe İlişkin Birinci Düzey Çok Faktörlü DFA Modeli

Çalışmada ayrıca ikinci düzey (üst düzey) çok faktörlü DFA yapılmıştır. İkinci düzey DFA neticesinde elde edilen uyum iyiliği değerlerinin $\left(\chi^{2}[147\right.$, $\mathrm{N}=500]=659.992 ; p<.01 ; \chi^{2} / \mathrm{sd}=4.490$; RMSEA $\left.=.084 ; \mathrm{CFI}=.920 ; \mathrm{GFI}=.895\right)$ önerilen 6 faktörlü modelin verileri ile uyumlu ve kabul edilebilir olduğu görülmektedir (Şekil 2). Hem birinci düzey hem de ikinci düzey DFA'dan elde edilen sonuçların, literatürde yer alan uyum iyiliği değerleriyle uyumlu olduğu görülmüştür. Ancak her iki düzeydeki (birinci düzey DFA ve ikinci düzey DFA) analizler birbirine yakın değerler aldığında daha az karmaşık olan model kullanılabilmektedir (Gürbüz ve Şahin, 2018). Dolayısıyla bu ölçek için birinci düzey DFA modeli esas alınabilir. 


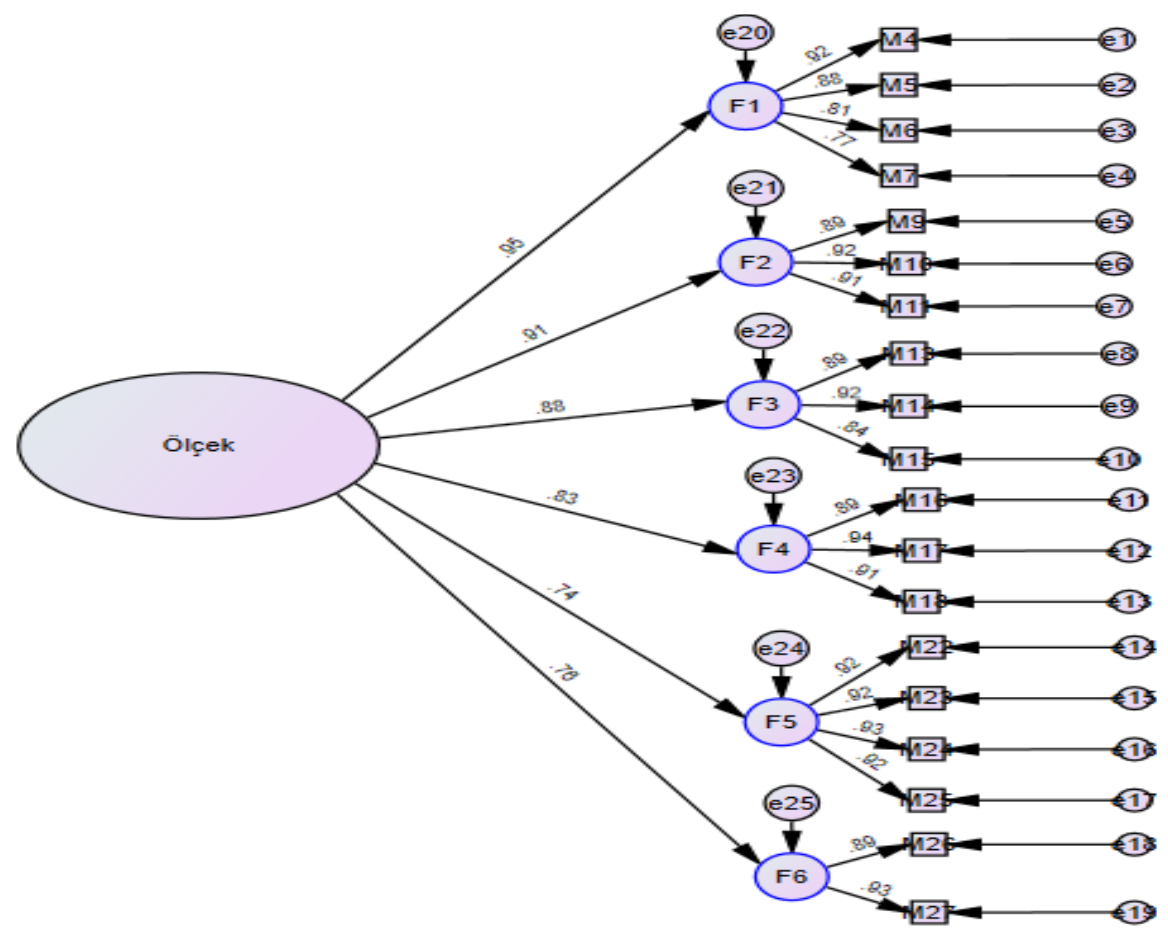

Şekil 2. Ölçeğe İlişkin İkinci Düzey Çok Faktörlü DFA Modeli

\section{Tartışma, Sonuç ve Öneriler}

Çok yönlü boyutlara sahip olan SBK'lar günümüz dünyasında eğitim işlevi açısından ele alınması gereken önemli bir meseledir. Özellikle son dönemlerde SBK'lar öğrencilerin bilimsel okuryazarlıklarının geliştirilmesi hareketi olarak görülmekte dolayısıyla SBK'ya yönelik duyuşsal niteliklerin ortaya çıkarılması gerektiği belirtilmektedir (Topcu, 2010). Bu doğrultuda ilk yıllardan itibaren öğrencilerin SBK eğitimlerine tabii tutulması ve bu yöndeki eğilimlerinin araştırılması önem arz etmektedir (Klaver ve van der Molen, 2020). Ancak ülkemizde eğitimlerinin henüz başında olan küçük çocukların SBK'ya yönelik tutumların belirlemeye yönelik geçerlik ve güvenirliği ispatlanmış bir ölçme aracının olmadığı tespit edilmiştir. Dolayısıyla bu amaçla ilgili literatürde daha önce geliştirilmiş bir ölçeğin Türkçeye uyarlaması çalışması yapılmıştır. 
Uyarlaması yapılan orijinal ölçek 27 madde ve 8 faktörlü bir yapıya sahiptir. Uyarlama sonucunda ilgili ölçek 19 madde ve 6 faktörlü bir yapıya bürünmüştür. Yapı geçerliliğinin test edildiği AFA'da 2 maddenin normallik varsayımlarını karşılamadığı görülmüş ve bu maddeler analize dahil edilmemiştir. Devam eden analizde faktör yükleri .30 'n altında kalan ve birden fazla faktörde yer aldığı tespit edilen binişik maddeler ölçekten çıkarılmış ve AFA tekrarlanmıştır. Orijinalinden farklı olarak uyarlama sonucunda ölçeğin 6 faktörlü yapıda, \%78.677'lik varyans açıklaması olduğu ayrıca ölçeğin geneline ait iç tutarlılık katsayısının .941 olduğu görülmüsstür. Ulaşılan değerler dikkate alındığında çocukların SBK'ya yönelik tutumlarını belirlemeye yönelik olarak ölçeğin yeterli olduğunu söylemek mümkündür (Tavşancil, 2014).

AFA ile elde edilen sonuçlara dayalı olarak ilgili faktör yapısı DFA ile test edilmiştir. İlgili test sonucu, AFA ve DFA değerlerine ait faktör yapıs1nın uyumlu olduğunu göstermiştir. DFA sonucunda elde edilen CFI (.967), IFI (.967) ve GFI (.931) uyum iyiliği değerlerine göre faktör yapısı mükemmel uyum göstermektedir (Seçer, 2015). Ayrıca $\chi^{2} /$ sd (2.51) istatistiği ile RMSEA (.055), NFI (.947), AGFI (.904) ve RMR (.021) uyum iyiliği değerlerine göre DFA ile oluşturulan faktör yapısının iyi uyuma sahip olduğu tespit edilmiştir.

AFA ve DFA sonucunda orijinal ölçekte yer alan "kurumsal ilgi" ve "özyeterlik" faktörlerinin uyarlanan ölçekte yer almadığı görülmektedir. Ayrıca orijinal ölçeğin "olumlu duygular" faktöründe yer alan 12. madde de ölçekte yer almamaktadır. Bu durum verilerin toplandığı örneklemin özellikleriyle ilgili bir durum olabilir. Bununla birlikte orijinal ölçekte son faktör yapısı altında 2 madde yer almakta olup uyarlama çalışmasında da bu iki maddenin faktör yüklerinin oldukça yüksek olduğu görülmüş̧tür (.873 ve .863). Dolayısıyla bu faktörün 2 maddeli yapısına sâdık kalınmıştır.

Türkçeye uyarlaması yapılan bu ölçekle öğrenimlerinin henüz başlarında olan ilk ve ortaokul çağındaki çocukların SBK'ya yönelik tutumları incelenebilir. Böylece sadece nicel çalışmalarda değil nicel çalışmalardan elde edilecek sonuçların açiklanması amacıyla karma çalışmalarda da kullanılabilecek geçerli ve güvenilir bir ölçme aracı elde edilmiştir. İlgili ölçme aracı ile elde edilecek veriler, program uzmanları, öğretmenler ve politika geliştiriciler için detaylı ve eleştirel bir bakış açısı sunabilir. 


\title{
EXTENDED ABSTRACT
}

\section{The Study of Validity and Reliability of Pupils' Attitudes towards Socioscientific Issues Scale}

\author{
Menşure Alkış Küçükaydın- Yasin Gökbulut- Dilek Şahinpınar \\ Necmettin Erbakan University -Gaziosmanpaşa University- Ă̆gr İbrahim Çeçen University
}

Students' involvement in science and their learning of science in daily life have been associated with socioscientific issues (SSI) in the relevant literature. SSI involves the deliberate discussion of scientific issues from different contexts. However, the attitudes, ethical and moral judgments of the students are very guiding on the students' final decisions to be reached in these discussions. There is no clear solution to the selected issues in the context of SSI, so this situation requires students to actively participate in the SSI discussions. In SSI discussions, students develop their own value judgments and thus add their feelings to the process. Because different value judgments are involved in the discussions, students are confused and experience emotional conflict until the final decision is reached. Therefore, SSI discussions affect students both cognitively and affectively. Especially in children, these effects should be examined with valid and reliable measurement tools. In this study, it was aimed to adaptation a measurement tool to Turkish language and culture, which is included in the relevant literature and developed to reveal pupils' attitudes towards SSI. In the study, a scale that conducted by Klaver and van der Molen (2020) with Dutch students and then translated into English was adapted to Turkish. Thus, the study validity and reliability of the relevant scale was carried out and the real factor structure was determined after the adaptation. The adapted scale was developed to be used in studies with pupils aged 8-15. Scale that consists of an 8-factor structure: relevance institutions, personal relevance, relevance school, positive feelings, concern, self-efficacy, collective efficacy and dependency on others. There are 27 items in the 4 point Likert type scale.

In this study, survey design, one of the quantitative research methods, has been adopted. The universe of the study consisted of 4th, 5th, 6th, 7th and 8th grade students studying in Konya and Tokat in the 2020-2021 aca- 
demic year. Since the universe of the research is large, the study sample was created through stratified sampling, one of the probabilistic sampling types. A total of 500 students participated in the study. In the study, data were collected with the help of the scale developed by Klaver and van der Molen (2020). Permission was obtained from the authors for the relevant scale and the scale adaptation process was initiated. Exploratory factor analysis (EFA) and confirmatory factor analysis (CFA) were used in the adaptation process of the measurement tools.

Kaiser-Meyer-Olkin (KMO) and Bartlett tests were carried out in order to test the suitability of the scale to be adapted to EFA. The relevant test results showed that the KMO value was .894 and the Barlett test was significant at the $\mathrm{p}<.01$ level, so EFA should be make for the scale data. After this stage, factor analysis was started in order to reveal the implicit structure of the scale through the relevant data set. Principal components analysis method was used to reveal the factor structure of the relevant scale. Outline values, normality and multiple linearity analysis were made. Two items (1 and 8) that did not meet the normality assumptions that's why excluded from the analysis. Assuming that the factors in the scale are related to each other, varimax, one of the orthogonal rotation techniques, was used. As a result of the EFA, which was carried out considering these issues, 6 factors were obtained with an eigen value higher than 1 . The total variance explained by the factors of the scale is \% 78.677. In this context, it was seen that the total correlation values of the items ranged between .878 and .545 . As a result of the internal consistency analysis of the scale, it was seen that the Cronbach's Alpa value for the whole scale was .941. Cronbach Alpha values for the factors $.787, .886, .859, .907, .944$ and .881 , respectively. In order to determine the relationship between the factors of the relevant scale, the correlation between factors was also examined. It has been observed that the relevant values are not over .90, so there is no multi-connection problem. According to the EFA conducted in the study, it was seen that the relevant scale has a structure with 6 factors and 19 items in total. This resulting structure was tested by CFA. The goodness of model fit values obtained as a result of the first level CFA, it was found that the proposed 6-factor model was compatible and acceptable with its data $\left(\chi^{2}[137, \mathrm{~N}=500]=346.891 ; p<.01 ; \chi^{2} / \mathrm{sd}=2.532\right.$; RMSEA=.055; CFI= .967; GFI= .931). Second level (high level) multifactorial CFA was also performed in the study. The goodness of model fit values 
obtained as a result of the second level CFA, it was found that the proposed 6-factor model was compatible and acceptable with its data $\left(\chi^{2}\right.$ [147, $\left.\mathrm{N}=500]=659.992 ; p<.01 ; \chi^{2} / \mathrm{sd}=4.490 ; \mathrm{RMSEA}=.084 ; \mathrm{CFI}=.920 ; \mathrm{GFI}=.895\right)$. As a result of EFA and CFA, it was seen that the "relevance institutions" and "self-efficacy" factors in the original scale were not included in the adapted scale. In addition, item 12 in the "positive feelings" factor of the original scale is not included in the Turkish scale. This may be a situation related to the characteristics of the sample from which the data were collected. However, there is a factor load of 2 items under the last factor structure in the original scale found to be quite high and also the factor loadings (.873 and .863) of these two items were high on the Turkish scale. Therefore, the 2-item structure of this factor is adhered to.

With this scale adapted to Turkish, the attitudes towards SSI of pupils who are just at the beginning of their education in primary and secondary school age can be examined. Thus, a valid and reliable measurement tool has been obtained that scale can be used not only in quantitative studies but also in mixed studies in order to explain the results to be obtained from quantitative studies. The data obtained with the relevant measurement tool can provide a detailed and critical perspective for program experts, teachers and policy developers.

\section{Kaynakça/References}

Akbaş, M. ve Çetin, P. S. (2018). Üstün yetenekli öğrencilerin çeşitli sosyobilimsel konulara ilişkin argümantasyon kalitesinin ve informal düşünme becerisinin incelenmesi. Necatibey Eğitim Fakültesi Elektronik Fen ve Matematik

Ĕ̆itimi

Dergisi,

12(1),

339-360.

https://doi.org/10.17522/balikesirnef.437794

Alkış Küçükaydın, M. (2019a). İlkokul öğrencileri fen bilimleri dersinde öğrendikleri bilgileri günlük yaşamlarıyla ne kadar ilişkilendirebiliyor? Abant İzet Baysal Üniversitesi Eğitim Fakültesi Dergisi, 19(2), 440-452. https://doi.org/10.17240/aibuefd.2019.19.46660-418986

Alkış Küçükaydın, M. (2019b). Sekizinci sınıf öğrencilerinin sosyobilimsel bir konuya ilişkin görüşleri ve argüman yapıları. Ilköğretim Online, 18(1),174-189. http://dx.doi.org/10.17051/io.2015.85927 
Alkış Küçükaydın, M. (2019c). Sınıf öğretmeni adaylarının sosyobilimsel konulara yönelik tutumları ile sorgulama becerileri arasındaki ilişkinin incelenmesi. Milli Ĕ̆itim Dergisi, 49(225), 181-200.

Atabey, N. and Topcu, M. S. (2017). The development of a socioscientific issuesbased curriculum unit for middle school students: Global warming issue. International Journal of Education in Mathematics, Science and Technology, 5(3), 153-170. http://dx.doi.org/10.18404/ijemst.296027

Atasoy, Ş. (2018). Öğretmen adaylarının yaşam alanlarına göre yerel sosyobilimsel konularla ilgili informal muhakemeleri. Fen Bilimleri Öğretimi Dergisi, 6(1), 60-72.

Ayvacı, H.Ş., Bülbül, S. ve Türker, K. (2019). Fen bilgisi öğretmen adaylarının sosyobilimsel konular hakkındaki tutumlarının sınıf düzeyine göre incelenmesi. Ondokuz Mayıs Üniversitesi Ĕ̆itim Fakültesi Dergisi, 38(2), 1730. http://dx.doi.org/10.7822/omuefd.525453

Bozdağ, H. C. (2019). 5. sınıf öğrencilerinin fen bilimlerine yönelik motivasyonları, tutumları ve fen başarıları arasındaki ilişki. Mersin Üniversitesi Ĕ̆gitim Fakültesi Dergisi, 15(3), 720-740. https://doi.org/10.17860/mersinefd.592823

Büyüköztürk, Ş. (2011). Sosyal bilimler için veri analizi el kitabı (15. Baskı). Ankara: Pegem Akademi.

Büyüköztürk, Ş., Kılıç Çakmak, E., Akgün, Ö.E., Karadeniz, Ş. ve Demirel, F. (2011). Bilimsel araştırma yöntemleri (9.baskı). Ankara: Pegem Akademi.

Chowdhury, T. B. M., Holbrook, J. and Rannikmäe, M. (2020). Socioscientific issues within science education and their role in promoting the desired citizenry. Science Education International, 31(2), 203-208. https://doi.org/10.33828/sei.v31.i2.10

Elam,M., Solli, A. and Mäkitalo, A. (2019). Socioscientific issues via controversy mapping: bringing actor-network theory into the science classroom with digital technology. Discourse: Studies in the Cultural Politics of Education, 40(1), 61-77. https://doi.org/10.1080/01596306.2018.1549704

Erkol, M. ve Gül, Ş. (2020). Fen bilgisi öğretmen adaylarının sosyobilimsel konulara yönelik tutumları. PESA Uluslararası Sosyal Araştırmalar Dergisi, 6(1), 9-21.

Everitt, B. S. (1975). Multivariate analysis: The need for data, and other problems. The British Journal of Psychiatry, 126(3), 237-240.

Field, A. (2005). Discovering statistics using SPSS (2nd ed.). New York, NY: Sage Publication. 
Gao, L., Mun, K. and Kim, S. W. (2019). Using socioscientific issues to enhance students' emotional competence. Research in Science Education, 1-22. https://doi.org/10.1007/s11165-019-09873-1

Gorsuch, R.L. (1983). Factor analysis (2nd ed.). Hillsdale, NJ: Lawrence Erlbaum Associates.

Gürbüz, S. ve Şahin, F. (2018). Sosyal bilimlerde araştırma yöntemleri (5. Baskı). Ankara: Seçkin Yayıncılık.

Hoyle, R.H. (1995). Structural equation modeling: Concepts, issues and applications. New York, NY: Sage Publication.

Klaver, L. T. and van der Molen, J. H. W. (2020). Measuring pupils' attitudes towards socioscientific issues. Science $\mathcal{E}$ Education, 30, 1-28. https://doi.org/10.1007/s11191-020-00174-y

Ladachart, L. and Ladachart, L. (2021). Preservice biology teachers' decisionmaking and informal reasoning about culture-based socioscientific issues. International Journal of Science Education, 43(5), 641-671. https://doi.org/10.1080/09500693.2021.1876958

Lee, H., Yoo, J., Choi, K., Kim, S. W., Krajcik, J., Herman, B. C. and Zeidler, D. L. (2013). Socioscientific issues as a vehicle for promoting character and values for global citizens. International Journal of Science Education, 35(12), 2079-2113. https://doi.org/10.1080/09500693.2012.749546

Milli Eğitim Bakanlı̆̆ı (2018). İlköğretim kurumları fen bilimleri dersi öğretim programı (İlkokul ve ortaokul 3.,4.,5.,6., 7. ve 8.sinıflar). Ankara: Devlet Basımevi.

National Research Council (2011). A framework for K-12 science education: Practices, crosscutting concepts, and core ideas. Washington, DC: National Academies Press.

Ocak, İ. ve Erbasan, Ö. (2017). 4. Sınıf öğrencilerinin fen bilimleri dersine yönelik tutumları ve epistemolojik inançları. Afyon Kocatepe Üniversitesi Sosyal Bilimler Dergisi, 19(2), 187-207.

OECD. (2014). PISA 2012 results: What students know and can do (Student performance in mathematics, reading and sciences). OECD Publications.

Özden, M. (2020). Elementary school students' informal reasoning and its' quality regarding socio-scientific issues. Eurasian Journal of Educational Research, 20(86), 61-84. https://doi.org/10.14689/ejer.2020.86.4

Raveendran, A. (2021). Invoking the political in socioscientific issues: A study of Indian students' discussions on commercial surrogacy. Science Education, 105(1), 62-98. https://doi.org/10.1002/sce.21601 
Rubini, B., Ardianto, D., Setyaningsih, S. and Sariningrum, A. (2019, June). Using socio-scientific issues in problem based learning to enhance science literacy. In Journal of Physics: Conference Series, 1233(1), p.012073. IOP Publishing.

Sadler, T. D. (2004). Informal reasoning regarding socioscientific issues: A critical review of research. Journal of Research in Science Teaching: The Official Journal of the National Association for Research in Science Teaching, 41(5), 513-536. https://doi.org/10.1002/tea.20009

Sadler, T. D. (2011). Situating socio-scientific issues in classrooms as a means of achieving goals of science education. In T. D. Sadler (Ed.), Socio-scientific issues in the classroom: Teaching, learning and research (p.1-9). Dortrecht: Springer.

Seçer, İ. (2013). SPSS ve LISREL ile pratik veri analizi: Analiz ve raporlaştırma. Ankara: Anı yayıncilı.

Seçer, İ. (2015). Psikolojik test geliştirme ve uyarlama süreci. SPSS ve LISREL uygulamaları. Ankara: Anı Yayıncllk.

Sevim, S. and Ayvacı, H. Ş. (2020). Öğretmen adaylarının sosyo-bilimsel konulardaki inançları: Nükleer enerji. Eskişehir Osmangazi Üniversitesi Türk Dünyası Uygulama ve Araştırma Merkezi Eğitim Dergisi, 5(1), 25-39.

Sezgin Selçuk, G. (2019). Tarama yöntemi. H. Özmen ve O. Karamustafaoğlu (Ed.). İçinde Eğitimde araştırma yöntemleri (s. 140-161). Ankara: Pegem Akademi.

Tavşancıl, E. (2014). Tutumlarm ölçülmesi ve SPSS ile veri analizi (5.Basım). Ankara: Nobel Yayıncilik.

Tinsley, H. E. and Kass, R. A. (1979). The latent structure of the need satisfying properties of leisure activities. Journal of Leisure Research, 11(4), 278-291.

Topcu, M. S. (2010). Development of attitudes towards socioscientific issues scale for undergraduate students. Evaluation $\mathcal{E}$ Research in Education, 23(1), 51-67. https://doi.org/10.1080/09500791003628187

Türksever, F., Karışan, D. ve Türkoğlu, A. Y. (2020). Öğretmen adaylarının sosyobilimsel konular hakkındaki görüş ve tutumları ile dünya vatandaşlığına dair değer yargılarının incelenmesi. Başkent University Journal of Education, 7(2), 339-354.

Uyanık, G. (2017). İlkokul öğrencilerinin fen bilimleri dersine yönelik tutumları ile akademik başarıları arasındaki ilişki. TÜBAV Bilim Dergisi, 10(1), 8693. 
Xiao, S. and Sandoval, W. A. (2017). Associations between attitudes towards science and children's evaluation of information about socioscientific issues. Science E Education, 26(3), 247-269. https://doi.org/10.1007/s11191017-9888-0

Yerdelen, S., Cansiz, M., Cansiz, N. ve Akcay, H. (2018). Promoting preservice teachers' attitudes toward socioscientific issues. Journal of Education in Science, Environment and Health, 4(1), 1- 11. https://doi.org/10.21891/jeseh.387465

Zeidler, D. L. (2014). Socioscientific issues as a curriculum emphasis: Theory, research and practice. In S. K. Abell and N. G. Lederman (Eds.), Handbook of research on science education (p.697-726). Mahwah, NY: Routledge.

Zeidler, D. L. and Kahn, S. (2014). It's debatable! Using socioscientific issues to develop science literacy. Arlington, VA: NSTA Press.

Zeidler, D. L. and Nichols, B. H. (2009). Socioscientific issues: Theory and practice. Journal of Elementary Science Education, 21(2), 49-58. https://doi.org/10.1007/BF03173684 
EK: Çocukların Sosyobilimsel Konulara Yönelik Tutumları Ölçeğinin Maddeleri

\begin{tabular}{|c|c|c|}
\hline Alt Boyutlar & $\begin{array}{c}\text { Madde } \\
\text { Numaraları }\end{array}$ & Madde İfadeleri \\
\hline \multirow[t]{4}{*}{ Kişisel İlgi } & M1 & $\begin{array}{l}\text { Kişisel olarak, büyüdüğümde dünya sorunlarını çözmeye yardımcı olacak } \\
\text { olmamın çok önemli olduğunu düşünüyorum. }\end{array}$ \\
\hline & M2 & $\begin{array}{l}\text { Bana göre, büyüdüğümde dünya sorunlarının çözümüne yardımcı olabil- } \\
\text { mem çok önemlidir. }\end{array}$ \\
\hline & M3 & $\begin{array}{l}\text { Kişisel olarak, büyüdüğümde dünya sorunlarının çözümü için kendi } \\
\text { başıma bir şeyler yapacak olmamın çok önemli olduğunu düşünüyorum. }\end{array}$ \\
\hline & M4 & $\begin{array}{l}\text { Kişisel olarak, büyüdüğümde dünya sorunlarını çözmeye yardımcı olacak } \\
\text { olmama çok ihtiyaç duyulduğunu düşünüyorum. }\end{array}$ \\
\hline \multirow[t]{3}{*}{$\begin{array}{l}\text { Okul İlgi } \\
\text { Düzeyi }\end{array}$} & M5 & $\begin{array}{l}\text { Okulda dünya sorunları hakkında öğrendiklerimizin çok önemli olduğunu } \\
\text { düşünüyorum. }\end{array}$ \\
\hline & M6 & $\begin{array}{l}\text { Okulda dünya sorunlarını öğrenmenin çok önemli olduğunu düşünüyo- } \\
\text { rum. }\end{array}$ \\
\hline & M7 & $\begin{array}{l}\text { Okulda dünya sorunlarını öğrenmenin çok gerekli olduğunu düşünüyo- } \\
\text { rum. }\end{array}$ \\
\hline \multirow{3}{*}{$\begin{array}{l}\text { Olumlu } \\
\text { Duygular }\end{array}$} & M8 & Dünya sorunlarını araştırmaktan gerçekten keyif alıyorum. \\
\hline & M9 & $\begin{array}{l}\text { Dünya sorunları hakkında daha fazla bilgi edinmekten gerçekten keyif } \\
\text { alıyorum. }\end{array}$ \\
\hline & M10 & Dünya sorunları hakkında düşünmeyi gerçekten seviyorum. \\
\hline \multirow[t]{3}{*}{ Endişe } & M11 & Dünya sorunları hakkında gerçekten endişeliyim. \\
\hline & M12 & Dünya sorunları beni gerçekten endişelendiriyor. \\
\hline & M13 & Dünya sorunları hakkında çok endişeleniyorum. \\
\hline \multirow[t]{4}{*}{$\begin{array}{l}\text { Ortak Yeter- } \\
\quad \text { lik }\end{array}$} & M14 & $\begin{array}{l}\text { Sınıfımın dünya sorunlarına çözüm bulma konusunda çok iyi olduğunu } \\
\text { düşünüyorum. }\end{array}$ \\
\hline & M15 & Sınıfımın dünya sorunlarını tartışmada çok iyi olduğunu düşünüyorum. \\
\hline & M16 & $\begin{array}{l}\text { Sınıfımın dünya sorunları konusuyla ilgili bilgi toplama konusunda çok iyi } \\
\text { olduğunu düşünüyorum. }\end{array}$ \\
\hline & M17 & $\begin{array}{l}\text { Sınıfımın dünya sorunlarını araştırma konusunda çok iyi olduğunu düşü- } \\
\text { nüyorum. }\end{array}$ \\
\hline \multirow{2}{*}{$\begin{array}{l}\text { Başkalarına } \\
\text { Bağımlılık }\end{array}$} & M18 & Dünya sorunlarını araştırmak için başkalarının yardımına ihtiyacım var. \\
\hline & M19 & $\begin{array}{l}\text { Dünya sorunlarının çözümlerini düşünmek için başkalarının yardımına } \\
\text { ihtiyacım var. }\end{array}$ \\
\hline
\end{tabular}

\section{Kaynakça Bilgisi / Citation Information}

Alkış Küçükaydın, M., Gökbulut, Y. ve Şahinpınar, D. (2021). Çocukların Sosyobilimsel Konulara Yönelik Tutumları Ölçeğinin geçerlik ve güvenirlik çalışması. OPUS-Uluslararası Toplum Araştırmaları Dergisi, 18(Eğitim Bilimleri Özel Sayısı), 4930-4951. DOI:10.26466/opus.932976. 